\title{
Erratum to: Governance and Governed
}

\author{
Madhushree Sekher, S. Parasuraman and Ruth Kattumuri
}

\section{Erratum to:}

\section{Sekher et al. (eds.), Governance and Governed,} https://doi.org/10.1007/978-981-10-5963-6

The original version of the book was inadvertently published without the following corrections in Frontmatter:

In Copyright page, incorrect affiliation "Center for social exclusion and inclusive policies" of editor "S. Parasuraman" has been corrected as "Director, Tata Institute of Social Sciences".

In page (vii), order of the authors,

Madhushree Sekher

S. Parasuraman

Ruth Kattumuri

has been changed to read as

S. Parasuraman

Madhushree Sekher

Ruth Kattumuri

The erratum book has been updated with the changes.

The updated online version of the book can be found at https://doi.org/10.1007/978-981-10-5963-6 